\title{
PARA QUE SERVE ENSINAR FILOSOFIA NA EDUCAÇÃO DISCIPLINAR? PROJETO/INVENÇÃO DA APRENDIZAGEM FILOSÓFICA NO EDUCAR TRANSDISCIPLINAR
}

\section{Dante Augusto Galeffi ${ }^{1}$}

RESUMO: Trata-se de uma contribuição na direção da metamorfose do regime disciplinar de ensino vigente, tendo em vista a importância de uma formação filosófica própria e apropriada para o pleno desenvolvimento espiritual humano transdisciplinar. Critica-se o ensino da filosofia como "ilustração" e afirma-se uma filosofia como "criação" do aprender a pensar compartilhado, tendo em vista uma transformação humana comum-responsável pelo mundo da vida em sua totalidade una e múltipla simultaneamente. Partindo-se da falência do sistema de ensino disciplinar, desenvolve-se o argumento de um Educar Transdisciplinar em que a filosofia é compreendida como a atitude aprendente radical e criadora e não como uma disciplina isolada de um currículo fragmentário. Projeta-se uma linha utópica de formação humana tendo-se a filosofia como método de investigação e não como repetição de uma tradição ilustrada. Não se nega a importância dos clássicos e ilustres do pensamento, mas, sim, a forma de ensino vigente que não leva ao empoderamento pensante dos aprendizes. Afirmando-se um Educar Transdisciplinar em que o filosofar é o próprio 
método aprendente em todas as atividades, um saber para todos os aprendizes sem o qual ninguém conseguiria sair da caverna de Platão e a ela retornar transformado.

PALAVRAS-CHAVE: Educação Disciplinar; Educar Transdisciplinar; Atitude Filosófica; Atitude Aprendente Radical; Aprender Próprio e Apropriado.

ABSTRACT: This is a contribution towards the transformation of the disciplinary system in force for education, in view of the importance of proper and appropriate philosophical training for full human spiritual development transdisciplinary. Criticizes the teaching of philosophy as "illustration" and claims to be a philosophy as "creation" of learning to think shared, with a view to human transformation common-responsible for the world of life in a single totality and multiple simultaneously. Starting from the bankruptcy of disciplinary education system, develops the argument of a Educating Transdisciplinary in that philosophy is understood as the learner attitude radical and creative and not as an isolated discipline of a fragmented curriculum. Protruding a utopian line of human formation having to philosophy as research method and not a repeat of illustrated tradition. There is no denying the importance of classic and distinguished thought but the way of effective teaching that does not lead to thinking empowerment of learners. Claiming to be a Educating Transdisciplinary that philosophizing is the proper method learner in all activities, a knowledge to all learners without which no one could get out of Plato's cave and she returns transformed.

KEYWORDS: Disciplinary Education; Educating Transdisciplinary; Philosophical Attitude; Radical Learner Attitude; Learn Proper and Appropriate. 


\section{INTRODUÇÃO}

O ponto de partida para o que proponho discutir neste artigo é a constatação da falência do sistema de ensino disciplinar e como isto afeta o ensino de filosofia na educação básica nacional. Indo direto à questão crucial: por que os luminares da educação e da pedagogia não se deram conta de que a educação disciplinar é incompatível com os imperativos da emergente sociedade do conhecimento, da informação, da aprendizagem e do controle?

O que se pode constatar é que ainda não se ouve falar desta questão como algo evidente, e isto porque quem está imerso em determinado sistema modelador de comportamentos como aquele da educação disciplinar não tem condições de perceber outros níveis de Realidade. É como a alegoria da caverna de Platão, que continua sendo um marco na compreensão da diferença entre o estado de ignorância da verdadeira realidade e o estado de conhecimento de uma realidade ampliada. Para quem está imerso na práxis disciplinar da educação escolar é como se a Realidade fosse constituída de partes isoladas que são reunidas por soma simples sem nenhum salto exponencial. Assim, os múltiplos conhecimentos humanos produzidos ao logo da história social da humanidade se encontram armazenados em compartimentos estanques que formam o currículo disciplinar. Cada área com seus conteúdos específicos e seus trejeitos metodológicos procura afirmar a sua identidade, que consiste no reconhecimento do seu corpus disciplinar exclusivo e na garantia de sua objetividade científica. Fica improvável para quem está imerso na "caverna disciplinar" desenvolver pela investigação uma saída do lugar 
habitual, por meio de uma distância epistemológica sempre requerida para a efetuação de qualquer pesquisa rigorosa acerca dos fenômenos, portanto, daquilo que afeta o ser humano em sua constituição complexa, ecológica, biológica, ontológica e antropológica a partir do seu modo de ser-aí.

Ora, para sair da caverna disciplinar é preciso um ato criador semelhante ao que descreve Michel Serres (1990) a propósito dos saltos de natureza que ocorrem diante do aparentemente estabelecido como Realidade em determinado momento da história humana. Diz ele (SERRES, 1990, p. 162163):

Tales, Pitágoras, ou qualquer outro destes nomes de inicial, coloca-se, de uma hora para outra, fora do mundo. Fora deste mundo aqui, fora do real. Aí está a exterioridade máxima, a utopia radical, a anomalia, de que todas as outras serão, certamente, nada mais do que variedades. O que é inventado neste momento não é deste mundo, nem do mundo objetivo, nem do universo do discurso. Aqui não há ponto, nem reta, nem ângulo, nem triângulo. Da mesma forma que não há demonstração, nem univocidade no que é dito, nem no que circula entre nós. Platão não diz nada de diferente, na sua língua, e dizemos a mesma coisa, certos de que afirmamos uma outra. O lugar noético ou inteligível é separado, como que cortado com um machado, do espaço ou do mundo sensível, e este, no entanto, participa do primeiro, como se não pudesse existir sem ele, por ser atravessado pelo turbilhão relativista e pelas contradições discursivas do juízo de percepção. Escutem agora com novos ouvidos os nossos 
historiadores da invenção: o iniciador coloca-se no exterior, chega-nos vindo do outro lado da fechadura, onde foi deixado, largado, repudiado; daí reestrutura em forma de novidade o conjunto normal em crise.

As palavras de Serres se referem ao que vem primeiro no processo do pensamento filosófico e tudo o mais seria simples repetição do mesmo: "A invenção das matemáticas é, aqui, a invenção absoluta, o rasgo da história, invenção que tornou possível todas as outras, não somente pela técnica, mas pelo gesto fundador" (1990, p. 164). Com isto, ele está se referindo à determinação de um paradigma de Realidade que configura o próprio absoluto, o resto é arranjo de inovação dentro das relações móveis do espaço, do sensível, do corpo. Entretanto, como seria a consideração de um plano de constituição do real com diferentes níveis de Realidade e diferentes níveis de percepção, em relação ao qual a matemática é um absoluto fechado em si mesmo, não podendo compreender a razão última dos seus próprios limites de espaço e tempo, de extensão e intensidade?

Quando afirmo a falência do sistema disciplinar da educação, faço-o compreendendo um salto de natureza em relação ao paradigma teorético nascido entre os primeiros pensadores gregos que tiveram um acesso direto ao absoluto matemático como conjunto de todas as leis reguladoras de um mundo ideal tornado geométrico em sua planificação. Nesta perspectiva o absoluto matemático encontra o seu oposto no relativo não matemático, o mundo sensível, volátil, efêmero. Mas é justamente este mundo sensível aquele que requer cuidado e atenção, porque a vida das ideias puras é dependente do mundo da vida para que encontre expressão. 
É na superfície da percepção que as coisas aparecem e desaparecem, dançam diante de nós como bailarinas.

Aqui temos uma concepção de filosofia como identidade em contraste com a concepção da filosofia como diferença. Como identidade, a filosofia permanece atrelada ao mundo matemático transposto para o mundo das formas ideais, sempre idêntico a si mesmo como absoluto que é. Como diferença, a filosofia é uma aventura criadora aberta que não afirma a lógica da polarização, mas, sim, a lógica da inclusão do terceiro termo. A compreensão desta operação corresponde a um salto de natureza no âmbito da própria história absoluta da razão ocidental. Significa saltar para fora do plano paradigmático da disciplinaridade científica que tem como suporte a quantificação matemática como correlato da computação cerebral. O salto significa uma abertura para um mundo complexo movido por diferenças e não por identidades fixas. Um mundo em que o ser humano é chamado a realizar a sua potencialidade na errância de seus afetos e de seus desejos primais na transitoriedade da vida finita, concreta. Mas a modelagem disciplinar é justamente o contrário da transitoriedade e da errância, pois é definida a partir da objetividade e da certeza, da homogeneidade e da ordem geométrica ao modo ainda euclidiano. O disciplinar moderno encontra ressonância na razão cartesiana em sua postulação metódica e intencionalmente absoluta, levando ao desenvolvimento do conhecimento setorizado em especializações que cada vez mais isolam as partes de um suposto todo indivisível. As disciplinas por áreas do conhecimento se impuseram na formação do currículo 
escolar moderno. Elas perderam de vista a subjetividade e suas agruras, sua caoticidade, imprecisão, confusão conceitual, o humano em sua concretude. Mas é justamente esta concretude da subjetividade que reclama a sua parte no processo evolutivo da espécie humana. E é uma parte corporalmente constituída e sensivelmente ativa como tudo o que é vivo.

No decurso do processo histórico ocidental moderno, o ensino de filosofia foi associado ao humanismo clássico e seus grandes textos literários, daí a familiaridade das letras com a filosofia nos cursos superiores de humanidades, em contraposição ao novo modelo científico que se impôs como definidor de uma Realidade homogênea, monológica e uniforme. O ensino de filosofia nas universidades e na educação básica passou a tratar dos clássicos da filosofia historicamente. Seguramente há aqui um antes e um depois de Hegel que elabora uma Filosofia da História através de uma Fenomenologia do Espírito (1992) para descrever os estágios do espírito absoluto ao longo do tempo histórico da espécie humana. Com Hegel, nasce o historicismo filosófico como uma extensão do historicismo de origem filológica, a partir da descoberta e tradução da vasta literatura do mundo antigo, especialmente aquela greco-romana que dava acesso renovado à concepção humanista clássica. $O$ fato é que as humanidades nas universidades européias do século XIX foram transpassadas pela compreensão histórica iluminada pelo idealismo absoluto de Hegel. Ler um pouco da escrita de Hegel permite compreender a importância da história em seu projeto de ciência absoluta. Diz ele no final da Fenomenologia do Espírito (1992, p. 220): 
O reino-dos-espíritos, que desse modo se forma no seraí, constitui uma sucessão na qual um espírito sucedeu a um outro, e cada um assumiu de seu antecessor o reino do mundo. Sua meta é a revelação da profundeza, e essa é o conceito absoluto. Essa revelação é, por isso, o suprassumir da profundeza do conceito, ou seja, sua extensão, a negatividade desse Eu que-em-si-se-adentra: negatividade que é sua extrusão ou [sua] substância. Essa revelação é seu tempo, em que essa extrusão se extrusa nela mesma, e desse modo está, tanto em sua extensão quanto em sua profundeza, no Si. A meta - o saber absoluto, ou o espírito que se sabe como espírito - tem por seu caminho a recordação dos espíritos como são neles mesmos, e como desempenham a organização de seu reino. Sua conservação, segundo o lado do seu ser-aí livre que se manifesta na forma da contingência, é a história; mas segundo o lado de sua organização conceitual, é a ciência do saber que-se-manifesta. Os dois lados conjuntamente - a história conceituada formam a recordação e o calvário do espírito absoluto; a efetividade, a verdade e a certeza de seu trono, sem o qual o espírito seria a solidão sem vida; somente

"do cálice desse reino dos espíritos espuma até ele sua infinitude". [Schiller]

Nessa passagem, encontra-se a pegada hegeliana da efetividade histórica do desenvolvimento do espírito humano, o que se impôs como horizonte teleológico de uma pretensa História Mundial que teria alcançado a totalidade de seus reinos no momento em que alguém alcançou a autoconsciência 
da ciência absoluta. E aqui se mostra o abismo entre o paradigma disciplinar e aquele transdisciplinar que requer não a construção de uma ponte para a sua transposição e sim um salto que o atravesse sem que a força de sua gravidade atraia para a perdição aquele ou aquela que ouse saltá-lo. O risco é grande, mas o espírito sem a vida não é absolutamente nada. E a vida quer mais-vida e não se satisfaz com ilustrações eruditas. O que quero dizer é que a abordagem histórica da filosofia modulou também os conteúdos de filosofia que passaram a ser ensinados na educação básica como História da Filosofia nas escolas européias do século XX e nunca como exercício filosófico próprio e apropriado. A grandeza das obras dos grandes luminares do pensamento filosófico, enfim, oferecida em lições na escola média para todos. Mas, em nenhum momento se propôs para a formação básica, como também para a superior, uma filosofia como filosofar fenomenológico, sempre partindo das coisas mesmas, aberto ao diálogo interrogante infinito, jamais conclusivo, sempre perplexivo, nunca absolutamente certo e sim provavelmente certo, imprevisível, aberto ao acontecimento dialógico na polilogia das vozes reunidas, tendo em vista metas comuns de desenvolvimento espiritual sustentável.

Então, pela tradição que nos alcança a todos, a filosofia na escola nunca foi um campo aberto para o empoderamento crítico das pessoas em formação e sim um território histórico com seus donatários e senhores de reinos bem definidos. Um corpus fechado de doutrinas cada uma das quais valendo como um sistema autônomo e independente dos outros tantos sistemas autônomos. Esta tem sido a filosofia ensinada nas escolas até agora. Mas, com qual propósito se ensina a História da Filosofia no lugar da prática filosófica dialógica? 


\section{ENSINAR FILOSOFIA COM QUAL PROJETO HUMANO EM VISTA?}

Até aqui procurei situar o recortar do objeto de minha intenção com este artigo, e como não há espaço para um aprofundamento sobre certos aspectos que já emergiram no texto até o momento, vou usar do recurso sintético para favorecer o desenvolvimento do argumento pretendido. Não sou contra o ensino de História da Filosofia e sim contra o modo como se ensina História da Filosofia nos currículos disciplinares. Então, nada contra esta nobre tradição histórica que tanto agregou valor favorecedor do esclarecimento da aventura espiritual humana ao longo do seu breve tempo histórico, porque agora se apresenta de novo uma Grande História, outra metanarrativa. Entretanto, o modo de ser desta nova metanarrativa não mais depende da filosofia da identidade, pois se mobiliza como filosofia da vida e da diferença. Assim, não acredita mais no excesso de história simplesmente passada adiante como transmissão, porque toda esta informação se encontra abundantemente disponível na web para todos, mas, sim, pela emergência de uma reforma radical do pensamento e de toda a educação até então estabelecida a partir do ensino ostensivo de conteúdos programáticos fragmentados.

Edgar Morin (2015) aproxima o que chama de reforma do pensamento com a transdisciplinaridade, descrevendo a situação do modo de pensamento da fragmentação que caracteriza a disciplinaridade e, consequentemente, a escola disciplinar e também a filosofia escolástica da transmissão da sabedoria dos grandes da história. Diz ele (MORIN, 2015, p. 106-107): 
O modo de pensamento ou de conhecimento fragmentado, compartimentalizado, monodisciplinar, quantificador, nos conduz a uma inteligência cega, na mesma medida em que a atividade humana normal, empenhada em religar os conhecimentos, e sacrificada em prol da atitude não menos normal de separar. Devemos pensar o ensino a partir da consideração dos efeitos cada vez mais graves da hiperespecialização dos saberes e a incapacidade de articulá-los uns aos outros. [...] Em um circuito ininterrupto, conhecer implica separar para analisar e religar para sintetizar ou complexificar. Separatista, a prevalência disciplinar nos faz perder a aptidão para religar, a aptidão para contextualizar, ou seja, para situar uma informação ou um saber em seu contexto natural.

Lembramos ainda mais dessas condições pelo fato de que uma era planetária de intersolidariedade está em curso. Acrescentemos a isto que a disjunção histórica entre as duas culturas, a cultura das humanidades, que comportava a Literatura, a Filosofia, mas, sobretudo, uma possibilidade de reflexão e assimilação dos saberes, e a nova cultura científica, baseada na especialização e na compartimentalização, agrava as dificuldades que podemos ter para refletir sobre os saberes e, mais do que isso, para integrá-los.

Então, qual é o horizonte de formação da educação disciplinar posta e o que se pretende com o ensino de filosofia na educação básica nacional? Paremos para pensar. O retorno da Filosofia como disciplina obrigatória parece ter sido um avanço na intenção da educação formal de oferecer uma formação crítica e cidadã para todos. Os legisladores 
compreenderam a importância da Filosofia como campo do saber que lida com a investigação e o juízo crítico de todos os valores humanos. Mas, entre a intenção de introduzir uma filosofia capaz de agregar pensamento crítico na formação básica e as condições efetivas para tal há um fosso de profundidade abissal. O fato é que no regime disciplinar a Filosofia ganha um espaço restrito e isolado no conjunto das outras disciplinas, o que não permite de fato trabalhar a formação desejada para o desenvolvimento do pensamento crítico. Eis, então, a questão que se impõe: Como ensinar filosofia de modo que os estudantes tenham acesso ao pensamento crítico e possam formar uma consciência política e ética comum-responsável se o sistema disciplinar de ensino toma a filosofia como mais uma área com conteúdos diferentes das outras áreas que devem ser aprendidos pelos estudantes para realizarem provas?

Essa é uma descrição caricatural da situação, mas enfatiza o seu principal traço: a Filosofia não entrou para transversalizar as atividades curriculares como deveria ser a partir do trabalho com a atitude filosófica, e sim para preencher mais um campo disciplinar de conteúdos insulares. $\mathrm{Na}$ verdade é um desserviço o que tem acontecido, e isto porque o modelo da educação vigente parece uma roupa velha cheia de remendos, o que não resolve nada, apenas engana com a aparência de reforma. Afinal, quando é que se compreenderá o absurdo que é a educação disciplinar como está posta? Será preciso sair do horizonte paradigmático da disciplinaridade, como o prisioneiro da caverna de Platão que rompe os grilhões que lhe prendiam ao interior da caverna e se lança na descoberta do mundo ampliado, para 
compreender este absurdo? $\mathrm{O}$ que aconteceu ao prisioneiro quando se acostumou ao mundo fora da caverna e pôde pensar a sua situação anterior como absurda? Ora, basta que se desvele o horizonte teleológico da educação básica nacional para se flagrar o absurdo em sua efetividade. O que mostra este desvelamento?

Com ênfase, qual é a dúvida de que o horizonte final da educação básica tem sido a aprovação no ENEM? E a propalada formação crítica, como tem sido alcançada e avaliada com a inserção da filosofia no currículo da educação básica?

$\mathrm{Na}$ verdade o que se vê são as condições tenebrosas no interior da caverna disciplinar. O que se desvela é que não há um pensamento político de nação projetado para as emergências da sociedade telemática contemporânea. O que há são ajustes em forma de remendos que não permitirão sair do estado de calamidade social em que vive o Brasil de hoje. A reforma da educação é hoje uma emergência de primeira ordem. Mas é preciso sair da caverna disciplinar com seu paradigma monológico e sua concepção de Realidade reduzida para compreender isto.

Muito diferente é o que se encontra formulado na Declaração de Paris para a Filosofia (UNESCO, 1995), que se fosse levada a sério permitiria conceber uma educação filosófica básica em outra chave bem diferente da perspectiva atual da filosofia profissional. Trata-se de uma filosofia das ruas, para todos, e não para alguns eleitos senhores de reinos filosóficos com tarja de propriedade privada. Pelo contrário, o espírito da Declaração de Paris ultrapassa as fronteiras territoriais da geofilosofia alcançando a universalidade 
transcultural do pensamento humano, uma filosofia e um filosofar próprio e apropriado, contextualizado, globalizado e coletivamente autônomo. Vale citar algumas partes do texto remetendo à sua leitura integral que poderia muito bem servir como orientação para o trabalho com a filosofia na educação básica no caso em que não se restringisse a ser uma mera disciplina entre tantas outras e sim uma "disciplina" integradora de todo o saber (UNESCO, 1995, p. 13-14):

"Constatamos que os problemas de que trata a filosofia são os da vida e da existência dos homens considerados universalmente,

"Estimamos que a reflexão filosófica pode e deve contribuir para a compreensão e conduta dos afazeres humanos,

[...]

"Reafirmamos que a educação filosófica, formando espíritos livres e reflexivos [...]contribui para a paz e prepara cada um a assumir suas responsabilidades face às grandes interrogações contemporâneas, notadamente no domínio da ética,

"Julgamos que o desenvolvimento da reflexão filosófica, no ensino e na vida cultural, contribui de maneira importante para a formação de cidadãos, no exercício de sua capacidade de julgamento, elemento fundamental de toda democracia.

[...]

"Uma atividade filosófica livre deve ser garantida por toda parte - sob todas as formas e em todos os lugares onde ela possa se exercer - a todos os indivíduos; "O ensino de filosofia deve ser preservado ou estendido onde já existe, criado onde ainda não exista, e denominado explicitamente 'filosofia'; 
[...]

"Permanecendo totalmente autônomo, o ensino de filosofia deve ser, em toda parte onde isto é possível, efetivamente associado - e não simplesmente justaposto - às formações universitárias ou profissionais, em todos os domínios;

[...]

"O conhecimento das reflexões filosóficas das diferentes culturas, a comparação de seus aportes respectivos e a análise daquilo que os aproxima e daquilo que os opõe, devem ser perseguidos e sustentados pelas instituições de pesquisa e de ensino; [...]

Apresenta-se na Declaração uma concepção de filosofia que se oferece como horizonte formador de uma humanidade comprometida com o cuidado da própria vida em seus ritmos e ciclos, em seus avanços e retrocessos. E apesar da ênfase dada ao caráter disciplinar da filosofia, a Declaração aponta para uma qualidade transdisciplinar da filosofia quando reconhece o seu caráter ético e político e compreende a formação filosófica como conquista que permite a conversação e o diálogo com todas as formas espirituais que não atentem contra a dignidade da vida em geral. Uma reforma da educação começaria por uma reforma do modo como se trabalharia a filosofia como uma atitude aprendente radical, um aprender a pensar pelo questionar compreensivo e dialógico. Um aprender a pensar ao mesmo tempo laborioso e lento, prazeroso e veloz como Hermes, o Alado. 
A Declaração para a Filosofia não conseguiria se realizar no regime disciplinar da educação, sobretudo porque pensa a filosofia de modo transversal, o que implica no desenvolvimento de uma atitude aprendente como uma atitude filosófica. Assim, na filosofia não cabem partições e hierarquias de qualquer espécie, porque por nascimento ela é o âmbito cognitivo de reunião de todos os saberes. Assim, dentro desta concepção, a filosofia não pode ser uma disciplina isolada porque ela mesma é o método para se aprender a aprender. Um aprender a aprender, que é o mesmo que atitude filosófica. Em relação a este conceito Morin é muito feliz no modo como o delimita (2015, p. 128 129):

É necessário aprender a aprender, ou seja, aprender ao mesmo tempo separando e religando, analisando e sintetizando:

- a considerar os objetos não mais como coisas fechadas em si mesmas, mas como sistemas que se comunicam entre eles e com o meio circundante, e que essa comunicação faz parte de sua organização e de sua própria natureza;

- a ultrapassar a causalidade linear "causa-eefeito" para apreender a causalidade mútua, inter-relacional, circular (retroativa, recursiva), as incertezas da causalidade (porque as mesmas causas não produzem sempre os mesmos efeitos quando as reações dos sistemas afetados por elas são diferentes e porque causas diferentes podem suscitar os mesmos efeitos; 
- a compreender o desafio da complexidade que advém de todos os domínios do conhecimento e da ação, e o modo de pensar apto a a responder a esse desafio.

Compreendo o aprender a aprender como o filosofar posto-em-obra, o que também significa restaurar o sentido primevo da filosofia como amor pelo saber e ao mesmo tempo o reconhecimento do desconhecimento, portanto, o florescimento de uma racionalidade que tem consciência da consciência e da inconsciência. A própria atitude socrática diante do saber dos sábios: um saber não saber - a atitude filosófica própria e apropriada. Isto muda muita coisa, porque não se pode mais aceitar a filosofia como obra acabada e passada, porque ela é uma disposição da própria humanidade em conhecer e inventar modos de conhecimento capazes de transformar os modos de vida. Portanto é uma atividade criadora implicada em dar conta das emergências do mundo da vida a partir de uma racionalidade aberta ao sensível e atenta ao provável e não mais ao certo.

Ora, isso implica em uma mudança paradigmática que permita operar com a complexidade de modo rigoroso e ao mesmo tempo necessariamente inventivo, porque não tem nada concluído no mundo-aí. Mesmo que a sua efetividade seja aquela da dispersão e da fragmentação espiritual, ele é o único lugar em que se pode pretender reinventar a formação filosófica como atitude transdisciplinar. Isto requisita, também, outro desenho de formação do formador que estará atuando na educação básica com a atitude filosófica e não com a História da Filosofia Européia em primeiro 
lugar, o que acontecerá de modo espontâneo ao longo da própria educação básica, e não como imposição conteudista homogênea.

\section{A APRENDIZAGEM PRÓPRIA E APROPRIADA COMO "DIDÁTICA FILOSÓFICA MÍNIMA"}

Mas é preciso que se tenha um conceito de filosofia quando se utiliza o termo para indicar a atitude aprendente radical. O que é mesmo a filosofia? Eis uma questão que é sempre incômoda, apesar de tão corriqueira. É sempre preciso tomar um rumo nesta questão, definindo o uso do termo, e é sempre importante começar pelo dito e quase consumado. Segundo Deleuze e Guattari (2000, p. 13-14):

O filósofo é o amigo do conceito, ele é conceito em potência. Quer dizer que a filosofia não é uma simples arte de formar, de inventar ou de fabricar conceitos, pois os conceitos não são necessariamente formas, achados ou produtos. A filosofia, mais rigorosamente, é a disciplina que consiste em criar conceitos. [...] Criar conceitos sempre novos é objeto da filosofia. É porque o conceito deve ser criado que ele remete ao filósofo como àquele que o tem em potência, ou que tem sua potência e sua competência. Não se pode objetar que a criação se diz antes do sensível e das artes, já que a arte faz existir entidades espirituais e já que os conceitos filosóficos são também sensibilia. Para falar a verdade, as ciências, as artes, as filosofias são igualmente criadoras, mesmo se compete apenas à 
filosofia criar conceitos no sentido estrito. Os conceitos não nos esperam inteiramente feitos, como corpos celestes. Não há céu para os conceitos. Eles devem ser inventados, fabricados ou antes criados, e não seriam nada sem a assinatura daqueles que os criam. Nietzsche determinou a tarefa da filosofia quando escreveu: "os filósofos não devem mais contentar-se em aceitar os conceitos que lhe são dados, para somente limpá-los e fazê-los reluzir, mas é necessário que eles comecem por fabricá-los, criá-los, afirmá-los, persuadindo os homens a utilizá-los. Até o presente momento, tudo somado, cada um tinha confiança em seus conceitos, como num dote miraculoso vindo de algum mundo igualmente miraculoso", mas é necessário substituir a confiança pela desconfiança, e é dos conceitos que o filósofo deve desconfiar mais, desde que ele mesmo não os criou (Platão sabia isso bem, apesar de ter ensinado o contrário...). Platão dizia que é necessário contemplar as Idéias, mas tinha sido necessário, antes, que ele criasse o conceito de Idéia. Que valeria um filósofo do qual se pudesse dizer: ele não criou um conceito, ele não criou seus conceitos?

Temos aqui um bom exemplo do que significa criação filosófica. Para Deleuze/Guattari a filosofia cria conceitos e é uma disciplina específica, especializada, sendo o filósofo aquele que os fabrica no sentido estrito. O filósofo tem a potência e a competência para criar conceitos, e a filosofia é especificamente uma usina de fabricação/invenção/criação de conceitos. Sim, mas o que é o conceito como imaterial que se pode criar a partir de uma especialidade chamada filosofia? 
Assim como Deleuze e Guattari criaram o seu próprio conceito de conceito de filosofia, todos os filósofos também o fizeram de modos muito diversos e diferentes. A própria definição dada por eles para o conceito é uma criação que se desdobra pela identificação daquilo que não é conceito, mas percepto, afeto, juízo, função etc. No caso, é o próprio conceito de cada uma destas coisas que é resultado de uma criação filosófica. Entretanto, como aceitar isto sem procurar compreender as motivações desta determinada maneira de fazer filosofia que se apresenta como uma especialidade disciplinar? Já não seria o tempo oportuno de criar uma filosofia transdisciplinar como atitude aprendente radical, em que o conceito não seria uma exclusividade da filosofia e sim da mente humana em seus modos de subjetivação? Como, então, criar uma obra de arte sem conceitos e produzir ciência sem conceitos? Claro, uma filosofia dos perceptos e dos afetos seria a oficina conceitual do mundo da arte, mas o mundo da arte não precisa de conceitos filosóficos para ter sua própria atmosfera vital, assim como a filosofia não precisa do mundo da arte para existir. Trata-se de um jogo circular de dobras e redobras em que é preciso ter a potência do filósofo para se envolver e considerar como se aprecia uma obra de arte. É também uma "obra de arte" a arte dos conceitos porque sem conceito não há a própria arte, assim como o mundo, o cosmo, a pessoa, a sociedade etc.

Ora, os conceitos criados pelos filósofos povoam o mundo das palavras corriqueiras porque foram os filósofos que criaram o mundo como conceito. De certo modo, isto pode significar que o filósofo é o amante dos conceitos não importando em que língua fale, ou em que período da 
história humana tenha florescido. Haveria, assim, não apenas o filósofo ao modo grego, mas o "filósofo" como amante dos conceitos independente da língua que fale? E o poeta, não seria também, por ser um criador de palavras, um amante dos conceitos em forma de imagens?

A definição da especificidade da filosofia de Deleuze e Guattari se apresenta dentro da tradição filosófica ocidental, que alguns defendem ser a única tradição propriamente filosófica existente. Nesta tradição, a filosofia foi definida como uma atividade teorético-discursiva contraposta às atividades produtivas (poéticas) e práticas (políticas, éticas), e são os filósofos os criadores conceituais do mundo da vida, assim como os poetas foram e são os criadores do mundo paralelo da imaginação mítica e ficcional compreendida como mimesis do dinamismo da vida no plano das afecções da alma. Por isto não é simples definir o que é a filosofia, sendo mais apropriado falar daquilo que ela não é. Para Deleuze e Guattari (2000), a filosofia não é contemplação, nem reflexão, nem comunicação. Isto limita o campo da filosofia distinguindo-a de qualquer outra atividade criadora humana, o que requisita a figura do especialista em filosofia, seu operador conceitual. Desta forma, não seria a filosofia uma atividade criadora exclusiva dos filósofos profissionais, não cabendo nenhum uso indevido da filosofia como contemplação, reflexão e comunicação? A definição dada por Deleuze e Guattari é útil para o uso da filosofia na educação básica, ou ela só tem validade na filosofia profissional? Teríamos, então, filósofos (criadores de conceitos) e professores de filosofia (repetidores de conceitos criados)? Teríamos então uma filosofia transmitida por não filósofos e 
sim por peões da filosofia? Para qual finalidade se ensinaria uma filosofia criada pelos outros?

Minhas provocações têm um alvo certo: a desconstrução de todos os conceitos de filosofia construídos até então pelos filósofos luminares, para que seja possível construir uma filosofia própria e apropriada a partir do contexto local de cada aprendiz. E neste caso, a filosofia não é mais uma exclusividade do seu criador profissional e sim a abertura para o poder-saber-ser comum-pertencente e comumresponsável de todo ser humano singular. Parece também que a definição da filosofia como criação de conceitos é tão abrangente e vaga como definir a filosofia como o amor à sabedoria, ou como busca da verdade. O uso corriqueiro que se faz da palavra conceito vai indicar uma variedade de sentidos que dificilmente podem ser dissociados dos atos cognitivos comuns efetuados por qualquer ser humano em todos os instantes de sua vida, mesmo que no nível inconsciente de operação.

Então vejamos a variedade de usos da palavra. De maneira geral, o conceito é definido como um produto da faculdade de conhecer, portanto, a faculdade intelectiva e cognoscitiva do ser humano, correspondendo à mente, espírito e pensamento. O conceito também é associado á compreensão que alguém tem de uma palavra, noção, concepção, ideia. É também uma opinião, um ponto de vista, uma convicção, um dito original e engenhoso, um ditado, uma máxima, uma sentença. Pode ser também uma conclusão moral de um conto ou narrativa afim, assim como uma ideia ou dito conciso, um resumo. Usa-se também a palavra para indicar a reputação de alguém por parte do grupo de suas relações, 
da sociedade, referindo-se à sua fama. A palavra também se presta para indicar o sistema de avaliação simplificada em que são usadas as cinco primeiras letras do alfabeto no lugar da nota numérica. Já no campo específico da filosofia, a palavra assumiu muitos outros sentidos. O mais comum é aquele que o define como "representação mental de um objeto abstrato ou concreto, que se mostra como um instrumento fundamental do pensamento em sua tarefa de identificar, descrever e classificar os diferentes elementos e aspectos da realidade" (HOUAISS, 2000, p.783). A palavra tem um sentido central na tradição racionalista que vai de Platão até Hegel, significando a manifestação da essência ou substância do mundo real. Há também a tradição que atravessa o estoicismo grego, o nominalismo medieval e o empirismo moderno que define o conceito como um signo ou representação linguística que mantém uma relação de sentido com os objetos do conhecimento, relação não-ontológica. Nesta linhagem, a palavra designa a noção abstrata contida nas palavras de uma língua para designar as propriedades e características de uma classe de entidades abstratas, objetos ou uma classe de seres. Neste sentido, um conceito possui extensão e compreensão. A extensão é o número de elementos de uma classe e a compreensão é o conjunto dos caracteres de uma definição, sendo, assim, a capacidade de detalhamento ou foco dos casos específicos. A palavra em latim é um derivado do verbo conceptus significando a ação de conter, ato de perceber, germinação, fruto, feto, pensamento. E é ainda curioso ver os significados do antepositivo cap-, um derivado do verbo capère, que significa tomar, agarrar, pegar, apanhar, apossar-se, apoderar-se, sofrer, padecer, ser 
impedido, ganhar, cativar, chamar a si, seduzir, enganar, iludir, escolher, eleger, conter, encerrar, levar, admitir, comportar, conceber, entender; ganhar, alcançar, chegar a, obter etc. (HOUAISS, 2001).

Entretanto, nenhuma dessas definições diz respeito ao que Deleuze e Guattari querem dizer com conceito. E não é fácil compreender o que é mesmo o conceito fabricado como o definidor da filosofia. Como síntese, eles estão se referindo aos grandes criadores de filosofia, cada um dos quais cria conceitos como seus personagens, e os conceitos assim criados formam o plano de imanência de sistemas filosóficos inteiros. Assim, o conceito de Ideia em Platão é o plano de imanência de toda a sua doutrina filosófica, do mesmo modo como a Vontade de Potência ou o Eterno Retorno de Nietzsche são suas grandes invenções conceituais. Significa também que a criação de conceitos não é algo de que se tenha a fórmula de fabricação e, portanto, não pode ser ensinado. Filosofia neste sentido não pode ser ensinada. E se a filosofia é a criação de conceitos, na perspectiva dos autores não quer dizer que todos possam aprender a criar conceitos, porque só os filósofos criam conceitos, os cientistas criam funções, os artistas criam afetos e perceptos, e acrescento, os economistas e comerciantes criam dinheiro, as mães criam filhos etc. Há uma especificidade definida que só alcança os filósofos. Só os filósofos criam conceitos. Para que, então, ensinar filosofia sem o acesso ao filosofar através dos textos dos filósofos?

Na educação disciplinar, concebe-se o ensino de filosofia através de conteúdos que dizem respeito às múltiplas dimensões da filosofia em sua historicidade. Idealmente 
falando, é a oportunidade de tratar de temas de ontologia, de ética, de estética, de política, de linguagem, de lógica etc., o que alguns extraordinários educadores e educadoras da educação básica realizam magistralmente mesmo no regime disciplinar. O problema começa quando se pretende um programa uniformizado nacional, com livro didático e tudo. Aí o bicho pega. Como aprender filosofia sem filosofar? Por que impor um programa homogêneo para todos? E aqui o filosofar não é o mesmo que se tornar filósofo na acepção de Deleuze e Guattari, e por isso o ensinar filosofia tem de se tornar um filosofar, isto é, um exercício investigativo permanente e livremente escolhido, não obrigatório, mas não ao modo dos estudos profissionais em nível superior. Para que, afinal, obrigar as pessoas a estudarem a filosofia dos outros, quando o importante é propiciar as condições para que todos aprendam a pensar não pelos cânones de uma filosofia escolástica e sim pela abertura da experiência dialógica radical, que analisa e elabora sinteticamente uma hermenêutica dos conceitos através das "coisas mesmas"? Para que ensinar filosofia sem experiência filosófica?

Cabe, então, a proposição de uma alternativa ainda longínqua de um educar transdisciplinar para o qual a atitude filosófica é o mesmo que atitude aprendente radical: uma atitude que aprende o que não está dado e precisa ser inventado, fabricado, criado. Não se trata da filosofia deleuziana ou nietzschiana que pode ser estudada por cada um segundo a sua decisão e não seguindo a imposição dos outros, e sim da filosofia própria e apropriada: filosofia como atitude aprendente radical. 
Mas aqui aparece de novo a questão da especificidade da filosofia que segue as suas tradições históricas e seus filósofos, levando a supor que seja esta a filosofia que deve ser ensinada e ponto final. Eis aí ainda o paradigma disciplinar atuando. Eis, no fundo, a defesa de uma filosofia diferente daquela proclamada pela Declaração de Paris aqui citada para efeito de contraste. Ora, de que modo a filosofia profissional pode ser importante na formação básica se ela não se tornar formativa, se ela não inventar os seus próprios instrumentos e conceitos de aprendizagem a partir de sua própria práxis formativa? Por isto a importância do profissional de educação aprender a filosofar. Mas, como ficaria a especificidade da filosofia se todo educador aprendesse a filosofar em sua práxis podendo ser considerado primacialmente um filósofo ou filósofa?

\section{0 NÃO-ENSINO DE FILOSOFIA NO EDUCAR TRANSDISCIPLINAR}

Pensando, então, em uma alternativa de formação transdisciplinar, o que implicaria em uma real metamorfose do sistema de ensino para sistema de aprendizagem, afirmo que não se pode ensinar filosofia, mas se pode aprender a fazer filosofia filosofando. $E$ isto desde as crianças e a partir das próprias coisas, quer dizer, daquilo que afeta cognitivamente as pessoas em suas circunstâncias existenciais. Do mesmo modo como se pode aprender música ou outra atividade específica qualquer, e como esta compreensão está em desacordo com o que se tem feito com o ensino da filosofia no paradigma disciplinar, proponho 
um Educar Transdisciplinar em que o filosofar é o método aprendente para tudo o que se possa aprender. Trata-se do que chamei apropriadamente de Didática Filosófica Mínima para a aprendizagem de qualquer área do conhecimento. Isto significa também reinventar a própria filosofia em sua vocação e dimensão formativa abrangente, globalizadora e cosmopolítica inalienável: uma formação para a transfor mação permanente de tudo o que é fenômeno, portanto, de tudo o que alcança e afeta o ser humano em sua existência fática a partir de sua percepção em movimento. Defendo, assim, a concepção de uma filosofia da transformatividade criadora humana, o que requer por primeiro deixar ser o aprendiz o caminho de sua vida desejante.

É evidente como não há filosofia e filosofar sem Eros e sem laços afetivos entre amigos do saber, portanto, buscadores de algo supostamente perdido em alguma origem remota. Uma origem que para ser recordada precisa de uma motivação de tipo ontológico, como um programa já construído de possibilidades dentro de limites concretos, como, por exemplo, uma recordação de algo que foi esquecido com o nascimento no corpo humano e seu ambiente vital. Uma anamnese laboriosa e improvável, porque não há início que não esteja no presente vivo dos acontecimentos temporais. Mas de qualquer modo, o filósofo continua sendo aquele que se busca a si mesmo. Eis uma questão espinhosa e pouco seguida na tradição escolástica ocidental e muito menos na escola disciplinar.

Heráclito (2002) já havia identificado o sentido da filosofia ao dizer "Eu busco a mim mesmo" (Fragmento CVI), assim como afirmava que "Pensar é comum a todos" 
(Fragmento XXVIII). Ora, é evidente como na modernidade a filosofia deixou de ser uma busca pessoal do filósofo para se tornar uma técnica de argumentação a serviço de uma formação intelectual humanista. Difícil, então, restaurar o elã primal da filosofia como aspiração ao des-velamento de si mesmo, o alcance da vida sábia, pois agora a filosofia tornou-se um território disciplinar com seus profissionais especializados e não ainda uma possibilidade formativa para o florescimento sapiencial do ser humano a partir do seu próprio mundo vital. Nas entrelinhas, para Deleuze e Guattari a filosofia é coisa exclusiva dos filósofos criadores, e a sua criação não é algo que possa ser ensinado na escola como se ensina tabuada ou geografia, ou qualquer outra disciplina objetiva. Sendo uma coisa exclusiva dos filósofos, significa que a filosofia se identifica com o estilo literário de cada um deles, o que é uma criação pessoal como no mundo da arte personalizada e assinada. Nesta perspectiva, não se pode formar filósofos, o que seria um contra-senso, e sim profissionais especializados em textos de filósofos geniais. O filósofo é formado em sua própria invenção conceitual e não frequentando disciplinas filosóficas seriais. Significa que nem todos são filósofos ou querem ser, como nem todos são músicos ou querem ser. Construindo um plano de compreensão paralelo, é o mesmo que querer impor o ensino da Arte e suas expressões quando nem todos são artistas no sentido estrito. É como impor que todos aprendam música, ou dança ou teatro sem a mínima aptidão ou interesse. Por extensão, é impróprio querer impor qualquer coisa visando uma homogeneidade formal, assim como impor currículos fechados e obrigatórios sem levar em consideração as 
condições efetivas de aprendizagem em cada caso e lugar. Mas é justamente isto o que ocorre em nosso mundo: quem nele nasce está fadado a submeter-se às regras estabelecidas socialmente. Mas são todas regras criadas historicamente e por isto podem ser modificadas historicamente através das ações humanas.

Construindo uma alegoria, tendo saído da caverna disciplinar me encontrei diante de um mundo muito mais vasto e cheio de possibilidades desconhecidas. Pode ser que cada possibilidade uma vez atualizada se torne mais uma caverna. Pode ser que todo o universo com suas infindáveis galáxias e incontáveis sóis seja uma grande caverna dentro de tantas outras cavernas, porque a caverna é uma espécie de útero materno em que é gerado o tempo da vida. E a vida depende de sua ecologia corporal. Sair da caverna é simplesmente florescer na direção do que ilumina. Eis a saída para a vida: fora da caverna é a vida da consciência que se reconhece sob o sol, efêmera e finita, e o ser humano pode encontrar o seu lugar nesta passagem, pode ser passagem e não fim.

É com essa ressonância que penso a emergência de um Educar Transdisciplinar para o qual a filosofia é apropriada em sua abertura nascente radical, o que permite inclusive criar não apenas mais um conceito filosófico e sim um modo diferente de dispor o trabalho filosófico e seu sentido ontológico fundamental: libertar o ser humano das agruras do medo existencial de ser apenas um sopro evanescente e finito. Neste sentido, a filosofia de novo é um caminho de autoconhecimento na reforma em curso do pensamento, porque o lado que precisa evoluir não é o tecnológico e 
sim o afetivo. E este só pode ser considerado a partir do desenvolvimento espiritual dos seres humanos. A filosofia, assim, é um aprender a viver e a morrer, porque ninguém escapa do desaparecimento e ninguém está livre da eternidade: um paradoxo, eis o humano em suas dobras e redobras na incontornável força criadora que a tudo reúne e dispersa em igual medida, mas sempre para recomeçar. Sempre do início.

\section{CONSIDERAÇÕES INCONCLUSIVAS: FILOSOFIA COMO ATITUDE APRENDENTE RADICAL}

Ao conceber umEducarTransdisciplinar como emergência da condição humana planetária/mundial contemporânea, fica evidente para mim que a educação disciplinar funciona para um mundo ecologicamente insustentável, em que as pessoas se desconhecem ou só conhecem os seus próximos e familiares e acham que os outros não existem. E isto em um momento global em que a única via é a da sustentabilidade poliética e poliecológica. Isto significa que é preciso criar o educar para a sustentabilidade poliética (ética ambiental, social, mental e cibernética) um educar transdisciplinar que requer outra forma de compreensão do que é o desenvolvimento humano sustentável. Toda a concepção de formação necessária para a vida atual passa por uma radical transformação dos espaços de formação. Não são mais espaços de ensino e sim espaços de aprendizagem e transformação. Não há concessão para o ensino homogêneo, e por isso não uso o termo ensino-aprendizagem que ainda 
mantém a ênfase no ensinar sendo aí o aprender dependente do que se ensina e não ao aprender apropriador. Ora, o ensinar é o aprender no educar transdisciplinar porque nada há para ser ensinado no sentido ostensivo, e, sim, para ser mostrado e oferecido através da construção dos instrumentos cognitivos da aprendizagem, que é em si um ato aberto e intrinsecamente criador. A imitação se torna apropriação do criado na criação aprendente. A apropriação do criado é repetição da diferença: não há uma floração igual à outra. Cada momento em sua efemeridade é único e irrepetível. A repetição é a permanência do viver em seu querer-saber e em sua promessa de diferença.

Devo encerrar o que apenas iniciei a descrever como possibilidade de construção de um novo paradigma para orientar o desenvolvimento humano na direção de sua emancipação da caverna disciplinar. Concebo a filosofia como atitude aprendente radical e considero ser este o fio condutor para a reforma do sistema disciplinar de educação em sistema do educar transdisciplinar, o que requisita potência e ação para poder se fazer acontecimento. Teria muito ainda a falar desta proposição que compreende todo o educar a partir da atitude filosófica como atitude aprendente radical, mas alcancei o limite de caracteres permitidos.

\section{NOTA}

${ }^{1}$ Doutor em Educação pela Universidade Federal da Bahia (UFBA). Professor Titular da Universidade Federal da Bahia (UFBA), Departamento de Educação. E-mail: dgaleffi@uol.com.br 
PARA QUE SERVE ENSINAR FILOSOFIA NA EDUCAÇÃO DISCIPLINAR?...

\section{REFERÊNCIAS}

DELEUZE, G.; GUATTARI, F. O que é a filosofia? Rio de Janeiro: Ed. 34, 2000.

HERÁCLITO. Fragmentos contextualizados. Tradução, apresentação e comentários por Alexandre Costa. Rio de Janeiro: DIFEL, 2002.

HEGEL, G. W. F. Fenomenologia do espírito. Parte II. Petrópolis: Vozes, 1992.

HOUAISS. Dicionário Houaiss da Língua Portuguesa. Rio de Janeiro: Objetiva, 2001.

MORIN. E. Ensinar a Viver. Manifesto para mudar a educação. Porto Alegre: Sulina, 2015.

SERRES, M. Hermes: uma filosofia das ciências. Rio de Janeiro: Graal, 1990.

UNESCO. Philosophie et Démocratie dans le Monde - Une enquête de l'UNESCO. Paris: Librairie Génerale Française, 1995, p. 13-14. Disponível em: <http://bempensarparabemviver. blogspot.com.br/2010/12/declaracao-de-paris-para-filosofia. html>. Acesso em 24/06/2016 